\section{Determining the magnitude, controls, and mediators of microbial activity in shelf to abyssal marine sediments and implications for deep time}

\section{NICOLETTE R MEYER, ALMA E PARADA, BENNETT JAMES KAPILI AND ANNE E DEKAS}

Stanford University

Presenting Author: nrmeyer@stanford.edu

Marine sediment microorganisms comprise up to a third of the Earth's total living biomass [1] and influence atmospheric $\mathrm{O}_{2}$ and $\mathrm{CO}_{2}$ concentrations on geologic timescales. Despite considerable recent advances, significant questions regarding the magnitude, physicochemical controls, and mediators of benthic microbial activity remain unresolved, particularly in deep-sea sediments. Here, we combined $16 \mathrm{~S}$ rRNA sequencing with nearly $300{ }^{15} \mathrm{~N}$ and ${ }^{13} \mathrm{C}$ - tracer experiments to determine the rates and controls of total microbial anabolic activity, heterotrophy, autotrophy, and nitrogen fixation in sediments from $100-4500 \mathrm{~m}$ water depth in the northeastern Pacific and northwestern Atlantic Oceans, and modeled global anabolic activity rates from the Devonian to the present. We show that ammonium assimilation rates - a proxy of total anabolic activity - range from 0 to $0.20 \mathrm{nmol} \mathrm{N} \mathrm{ml}^{-1} \mathrm{y}^{-1}$, and correlate with distance from shore, chlorophyll a concentrations in the overlying water column, and depth in sediment. Although benthic nitrogen fixation was previously detected at deep-sea sites of anomalous carbon loading (e.g. in oxygen minimum zones, methane seeps, and whale fall sites [2, 3]), ${ }^{15} \mathrm{~N}_{2}$ assimilation was undetected in all samples, even with the addition of glucose. Generally, $10-20 \%$ of the microbial community's carbon assimilation was due to autotrophy. These nitrogen fixation and autotrophy data, as well as the results from experimental additions, are consistent with a benthic microbial community that is limited by carbon and/or energy availability, not by bioavailable nitrogen. The microbial communities are dominated by the activity of Deltaproteobacteria, particularly from the Desulfobacterales and Desulfurellales orders. Although these orders are associated with sulfate reducing bacteria, no sulfate reduction was detected in any samples, suggesting they use alternative metabolisms such as fermentation. We modeled the global distribution of microbial activity today (Figure 1) and extrapolated to the geologic past, and find that the magnitude of global benthic microbial activity is sensitive to supercontinental cycles, with implications for marine sediment organic carbon burial through deep time.

[1] Lipp et al. (2008), Nature 454, 991-994.

[2] Dekas et al. (2018), Environmental Microbiology 20, 4281-4296.

[3] Gier et al. (2016), Biogeosciences 13, 40654080.
A)

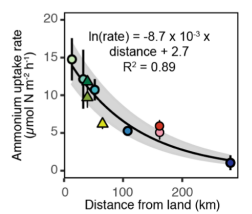

B)
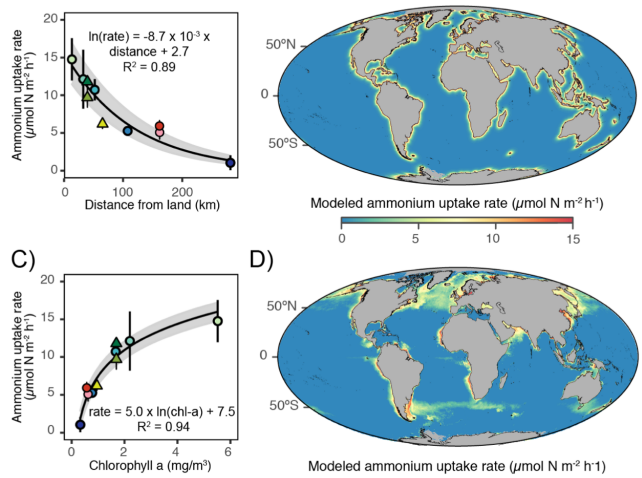

D)

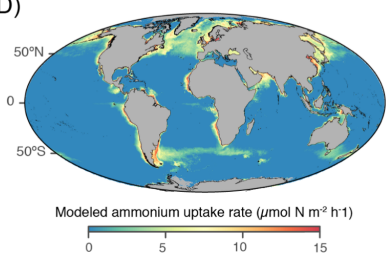

Figure 1: Global estimates of marine sediment microbial anabolic activity. A) Regression of distance from land and depth-integrated ammonium assimilation rates for the top $15 \mathrm{~cm}$ below the seafloor. Regression equation and $\mathrm{R}^{2}$ are indicated. Error bars $=1 \mathrm{SD}$ of the biological
replicates. The grey ribbon represents the model's $95 \%$ confidence interval. B) Map of xtrapolated, global ammonium assimilation rates using the regression in A. Total ammonium

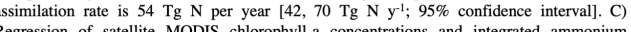
Regression of satellite MODIS chlorophyll-a concentrations and integrated ammonium assimilation rate. Rate data are the same as in panel A. D) Map of extrapolated, global $39 \mathrm{Tg} \mathrm{N}$ per year $\left[30,51 \mathrm{Tg} \mathrm{N}^{-1}\right]$. 